\title{
CIENCIA Y SER: PARADOJA E IRONÍA EN EL PROMETHEUS GOETHEANO
}

\author{
Víctor Castillo Morquecho \\ Instituto Tecnológico y de Estudios Superiores de Monterrey \\ vtorreonymty@hotmail.com
}

Recibido: 22 marzo 2012; Aceptado: 20 octubre 2012

Cómo citar este artículo/ Citation: Castillo Morquecho, Víctor (2013), "Ciencia y ser: Paradoja e ironía en el Prometheus goetheano", Asclepio 65 (1): p002. doi: http://dx.doi.org/10.3989/asclepio.2013.02

\begin{abstract}
RESUMEN: En este trabajo se parte del estudio de la figura de Prometeo durante la llustración, para entender su inserción en el contexto germano del Sturm und Drang. El énfasis recae en el Prometheus goetheano y en la relación que en esta obra se descubre entre el acto de conocer, la Naturaleza, y la realización del ser. Aquí, Prometeo es la figura del hombre ilustrado que busca superar, mediante la ciencia, las condiciones naturales y romper todo tipo de cadenas (políticas, religiosas, morales), pero este afán se ve siempre atravesado por "fuerzas irracionales». ¿Qué es lo que el hombre ha de aprender acerca de sí, dada la paradójica e irónica condición expresada en el Prometheus? Es lo que a continuación se espera responder.
\end{abstract}

PALABRAS CLAVE: Ciencia; Hombre; Naturaleza; Ironía; Paradoja.

SCIENCE AND BEING: PARADOX AND IRONY AT THE GOETHEAN PROMETHEUS

ABSTRACT: The point of departure in this paper is the study of Prometheus's figure during the European Enlightenment, in order to understand its insertion in the German context of the Sturm und Drang. The emphasis lays in Goethe's Prometheus and the relation that this poem exposes between Knowledge, Nature, and Self-realization. Here, Prometheus represents the enlightened man who, through science, search the mediums to surpass his natural conditions and break all kind of chains (political, moral or religious chains), but the problem is that his intention is always interfered by «irrational forces». ¿What man can learn about himself in this conditions of «irony» and «paradox» expressed in the Prometheus? That is the question that we expect to response here.

KEYWORDS: Science; Man; Nature; Irony; Paradox.

Copyright: (c) 2013 CSIC. Este es un artículo de acceso abierto distribuido bajo los términos de la licencia Creative Commons Attribution-Non Commercial (by-nc) Spain 3.0. 


\section{LA ERA PROMETEICA}

Hacia finales del siglo XVIII se presentan importantes cambios en el contexto germano. La guerra entre Viena y Prusia hizo más evidente que nunca la necesidad de un tipo de organización distinta al Imperio, pues el atraso político afectaba gravemente el comercio y la economía, y las guerras internas no hacían sino debilitar a una nación que se tornaba cada vez más susceptible. La necesidad de un cambio se confirmaba, además, mediante la sostenida expansión de los ideales ilustrados que, en medio de fuertes contradicciones, penetraron en el suelo germano, dando por resultado, entre otros, la paradoja de un "rey ilustrado", como Federico II, o la paradoja de una «ilustración religiosa» y mística, como la que se experimentaría durante el auge de la masonería y de la Orden de los lluminados, precisamente a fines del siglo XVIII (cf. Magee, 2001, pp. 53 y ss.). Si bien lo que en este caso hay que reconocer, es que a pesar de estas contradicciones, dicha penetración trajo consigo un nuevo optimismo filosófico a la burguesía alemana, basado en la creencia de que la realidad podía ser definida por la experiencia y acción individuales (cf. Brown, 1992, p. 483).

No de menor importancia fue, por su parte, lo que historiadores y filósofos de la historia han definido como el "pasaje en el tiempo» hacia finales del siglo XVIII (cf. Koselleck, 1985, pp. 238-239). En este momento el tiempo deja de ser concebido simplemente como el medio por el cual la historia tiene lugar y adquiere una cualidad "histórica», en donde se cobra consciencia de un movimiento "hacia adelante» que abre una división entre el pasado y el presente, al punto en que el presente toma el carácter de una nueva época. La expresión neue Zeit vino a circular en el siglo XVIII para designar no el tiempo presente, como el "aquí y ahora", sino como un periodo de transición en el cual lo nuevo y lo inesperado constantemente toman lugar, y será del peso que adquiere la experiencia y la acción individuales, así como del nuevo significado del tiempo, que se derivará, necesariamente, una obligación política: "This is the obligation of creatures whose lives hold a promise far greater than to be as mere leaves blowing in the wind, not to surrender the course of their existence to blind chance" (Michaelis, 1999, p. 542).

En este contexto, Prometeo, el dador del fuego (del conocimiento, la técnica y la civilización) vino a ser figura de la llustración europea, arrojando la luz de la razón humana sobre la superstición e iniciando a los humanos en las artes, en donde quedan representados el conocimiento, la técnica y la civilización:

"Most eighteenth-century texts emphasize Prometheus's role in engineering technological, and thus social, progress. A recurrent interpretation of the myth, as a so-called moral allegory, is of Prometheus as an exiled prince in savage Scythia. Pro- metheus teaches the primitive Scythians to make use of fire and helps them set up the first forges" (Jølle, 2004, pp. 398-399).

En el umbral del siglo XIX aparece Die Geschöpfe des Prometheus, op. 47, de Beethoven, una ambiciosa obra que intentaba producir una síntesis de la sinfonía, el oratorio y la ópera, en un género de teatro nuevo, el Ballo serio o musical danzado. Pero sería esta la última vez, nos dice Maine, "que en el mito de Prometeo prevaleciera el demiurgo sobre el héroe generoso y espantosamente castigado" (citado por Gómez de la Serna, 1996, p. 101). Pues la llustración es el momento en que se asume de frente el reto de la emancipación humana y Prometeo es símbolo de la afirmación del ser individual contra Dios y contra el mundo, " en el seno de la decadencia del mundo y de lo divino, del pesimismo y del nihilismo..." (Garcia Gual, 1995, pp. 191-192).

Gilbert Durand habla, además, de la relación entre el mito de Prometeo y el mesianismo mítico de finales del siglo XVIII y comienzos del XIX, para establecer la relación entre Napoleón y Prometeo (1993, p. 33). Se trata de una tendencia milenarista que arranca desde el siglo XIV, tras las "pruebas» que el Occidente cristiano ha vivido, a partir de lo cual resultaba inminente la llegada del Día del Juicio. Innumerables fechas fueron propuestas con relación a la definición y comienzo del "milenio», pero el hecho es que hasta los siglos XVII y XVIII, en medio de la Revolución Científica y la ilustración, cualquiera fuera la fecha favorecida, "Ios científicos creían firmemente que estaba terminando el periodo de 6.000 años de vida del cosmos, y que se preparaba el camino a cambios espirituales y tal vez también físicos" (Webster, 1988, p. 77). En el aspecto político, evidentemente también se esperaba un cambio, y no resulta extraño, entonces, que el Götz von Berlichingen (1773) de Goehte, una de las obras iniciadoras del Sturm und Drang ${ }^{1}$, tenga que ver con el confrontamiento frente al tirano, mientras que en el Prometheus de Bürger (1835), el fuego robado a los dioses viene a ser el símbolo, aunque ambiguo, del pensamiento "totalmente liberado» ${ }^{2}$.

La década de 1770 en Alemania ha sido llamada, propiamente, "la era de la rebelión prometéica» (cf. Leidner, 1989, p. 178), en tanto la rebelión pura tipificada por Prometeo, fue punto de referencia obligado para los escritores del Sturm und Drang. Vemos así, que el Guelfo de Klinger, en Die Zwillinge, lucha por la resolución de las inequidades en el sistema feudal y en la familia, mientras que en Die Räuber, Schiller enarbola la Freiheit! como el Leitmotiv en los "grandes planes» de Karl Moor. Tema, este último, de numerosas figuras, en donde la revuelta titánica contra la tiranía, es, en última instancia, la prueba del individuo contra el destino y en donde la fuerza y la voluntad individual es lo que prevalece. 
Característico es, sin embargo, que los personajes del Sturm und Drang expongan sentimientos que traicionan toda virtud, a tal grado que es la intransigencia, más que el altruismo, lo que llega a ser representativo del protagonista típico del Sturm und Drang, quien se mueve por la venganza, la ambición y la violencia. Guelfo y Karl Moor son asesinos, e incluso el Götz von Berlichingen de Goethe, con toda su virtud, lleva a cabo un traicionero ataque a las tropas del obispo y acepta dirigir la sangrienta rebelión de los campesinos $^{3}$. El Sturm und Drang deriva, entonces, en el Kraftmensch (fuerza del hombre), en el que se expresa la radicalización de una individualidad que parece no necesitar límites o autoridad alguna ${ }^{4}$.

Con lo que nos encontramos, por tanto, es con un enmarcado social en el que la situación política de Alemania demanda un cambio. Esta demanda es reforzada por los ideales ilustrados de libertad, que en Francia propician la Revolución y que en Alemania dan forma al Neue Zeit. Desde la religión y la ciencia se cree estar viviendo un nuevo tiempo que genera fuertes expectativas y Prometeo resurge, entonces, en la literatura y en arte Romántico en general, como símbolo de la libertad, del cambio, del enfrentamiento con las viejas formas. Siendo dador del fuego del conocimiento, surge además como símbolo de la «nueva ciencia», que en el contexto germano habrá que entender, como se confirmará más adelante, en relación con el saber del magus, que es capaz de elevar al hombre de su condición y de acercarlo al plano de los dioses ${ }^{5}$. Y creado este ambiente, no ha de resultar para nada extraño que la figura de Prometeo se convierta para Goethe, prácticamente en una obsesión ${ }^{6}$.

\section{GOETHE Y PROMETEO}

Partícipe, fundador y cabeza del Sturm und Drang, crítico de su tiempo y masón militante ${ }^{7}$, Goethe no hizo uno, sino cuatro intentos por trabajar el mito de Prometeo que, además del poema ${ }^{8}$, dieron por resultado obras fragmentarias o dramas inconclusos, como el iniciado hacia 1773 , o como el proyecto de drama de veintitrés líneas (1793) que lleva el título de Die Befreiung des Prometheus. Otras referencias a Prometeo en la obra de Goethe, dejan ver su constante preocupación sobre el tema, y el propio inacabamiento del drama de 1773, parece revelar un conflicto que inicia en su juventud y que no termina, quizá, más que en el Faustus (cf. Jølle, 2004, p. 400). Un conflicto entre la libertad y las normas (cf. Ehrlich, 1994, p. 792) que Brown define como un dualismo entre el Goethe rebelde y el Goethe crítico de la rebelión:

Goethe associates 'die größten Weltbegebenheiten' during his lifetime, including the great revolutionary movements from 1775 to 1830 , with the demonic. As processes of conflict and change, they frighten Goethe because they undermine the traditional order, which remains for him a social ideal. While Goethe acknowledges the inevitability and even productivity of change (the demonic can be 'wohltätig'), he dedicates himself to combating it aesthetically from 'hinter ein Bild' (1992, p. 487).

Una confluencia de motivos en donde, al parecer, más que buscar una solución, Goethe quiere plantear la condición del hombre, quien lidia entre la transgresión y la necesidad de algún tipo de orden. Pero ¿en qué consiste la rebelión planteada por Goethe en el Prometheus y en qué consiste el "orden» hacia el que pudiera apuntar?

La pista podría comenzar a dárnosla el estudio de las fuentes que Goethe utilizó para su Prometheus, pero en esto no hay acuerdo y, por principio, se mantiene como una cuestión sin resolver, el problema de si Goethe tuvo, o no, acceso a los originales griegos. No parece haber, por otra parte, rastro de que haya tomado para su Prometheus la Genealogía de Boccaccio, las referencias de Juan Pérez Moya, en su Philosophia secreta o La estatua de Prometeo de Calderón de la Barca, entre las obras clásicas del Renacimiento y la Ilustración. Sin embargo, de acuerdo a Jølle (2004), y como se logra entrever, tanto en el drama inconcluso, como en el poema de Prometheus, Goethe parece adherirse al trabajo de Hederich ${ }^{9}$ y, con ello, a la tradición proveniente de Esquilo ${ }^{10}$. Leidner habla, por tanto, del drama inconcluso de Goethe, como la más temprana versión romántica del Prometeo encadenado (1989, p. 178).

Conviene recordar, aquí, que puede considerarse que son tres los relatos fundantes que desde la Grecia clásica nos llegan en el tratamiento de Prometeo, a partir de los cuales se han hecho en Occidente numerosas reelaboraciones. En orden cronológico, estos son, la Teogonía y Los trabajos y los días de Hesíodo, el Protágoras de Platón y el Prometeo encadenado de Esquilo. La versión trágica de Esquilo, a diferencia del tratamiento hecho por Hesíodo ${ }^{11}$ y por Platón ${ }^{12}$, se distingue por situar a Prometeo como símbolo de la rebelión contra Zeus, representado como un tirano injusto.

En Esquilo, Prometeo viene a ser el prototipo del héroe cultural o civilizador que aporta al hombre todo lo que es útil y bueno: los cultivos, el fuego de cocina, las herramientas, las instituciones sociales y, sobre todo, le enseña las artes medicinales y adivinatorias. En una palabra, Prometeo libera de su condición natural al hombre, dándole las herramientas para enfrentar los azotes de la Necesidad y la Muerte, y lo acerca, con ello, al plano de los dioses.

No menos importante será el que Prometeo dote al hombre de la razón, del número y de la memoria, si bien en todo esto cabe subrayar, que el rasgo más 
característico en el Prometeo de Esquilo, será la capacidad del héroe para "dejarse afectar». Ciertamente se le castiga por haber robado el fuego (la «flor» de Vulcano), pero el propósito de este castigo es que Prometeo deje su comportamiento filantrópico (cf. García Bacca, 2001, p. 19; pp. 28-29).

La influencia de Esquilo, por tanto, se deja ver desde el momento en que el poema goetheano se reconoce como un "enfrentamiento», en donde el titán busca reafirmarse frente a los dioses. El Prometheus debe leerse, señala Jølle, como un "anti-himno", que desde el principio niega y desafía a los dioses usando la forma y el lenguaje tradicionalmente restringido para invocarles y honrarles (2004, p. 395).

La negación del poderío de Zeus adquiere, además, tintes de burla o ridiculización, en tanto la acción del gran soberano se ve reducida a la manifestación de meros caprichos. Los poderes de Zeus parecen servir, en último término, para ejercitar un tipo de destrucción infantil.

"Und übe, dem Knaben gleich,

Der Disteln köpft,

An Eichen dich und Bergeshöhn..."13.

Al igual que en Esquilo, en el poema de Goethe resulta preponderante la elevación del hombre por mediación de la ciencia, desde la cual el poder de los dioses se ve replegado y el propio Zeus parece dejar de tener influencia sobre la vida del hombre. Ahora, la casa y el fuego que la habita (símbolos de la técnica y de la razón o del conocimiento), y que Prometeo comparte con el hombre, le sitúan en una condición que trasciende su necesidad natural y le resguardan. Con esto seguro, Prometeo exige a Zeus:

\section{“Mußt mir meine Erde}

Doch lassen stehn

Und meine Hütte, die du nicht gebaut,

Und meine Herd,

Um dessen Glut

Du mich beneidest"14.

En esta rebelión, por tanto, se acusa el establecimiento de un orden, de un orden nuevo, de un orden "humano», en el que el saber o la ciencia prometeicos juegan un papel determinante. Nos encontramos aquí con la "elevación» del hombre al plano de los dioses, sí, pero tal elevación es posible por el saber que civiliza e independiza al ser humano.

\section{CIENCIA Y HUMANIZACIÓN}

Además del seguimiento a la línea trazada por Esquilo, en el caso que aquí nos ocupa conviene subra- yar el interés o la franca devoción de Goethe hacia la alquimia y la masonería, así como su interés recurrente en los signos, símbolos y significados que de la tradición hermética se desprenden (Gray, 1952, p. 15). De ellos resulta importante destacar, por un lado, el permanente intento del hermetismo por borrar la distinción entre Dios y el ser humano ${ }^{15}$ y, por otro, la intención sostenida por «actuar» en la naturaleza, en lugar de sólo "entenderla» (como sugeriría la tradición aristotélica), pues es de la capacidad de "actuar» sobre la naturaleza, por mediación del conocimiento, que toma forma y relieve la figura del mago (Hanratty, 1986, p. 308), aquel que adquiere tintes demónicos (sobrenaturales) por su acercamiento estrecho a Dios, a la Naturaleza o lo Trascendente.

La choza y el fuego, por tanto, no sólo son un «refugio», ni sólo son los primeros signos de la «dominio» de la naturaleza, de la aplicación de la ciencia a las necesidades humanas. Ambos, la choza y el fuego, protegen al ser humano de las variaciones del clima, pero al mismo tiempo, le acercan al conocimiento y al poder de los dioses e, incluso, al poder que les trasciende, en tanto ellos también se encuentran sujetos a la Necesidad (Garcia Bacca, 2001, p. 46) ${ }^{16}$, y superándola a ella, de algún modo el hombre se sitúa más allá de los dioses.

Estamos frente a un doble y paradójico movimiento que acerca y aleja al ser humano del mundo y de la condición de los dioses. El alejamiento es «suspensión» relativa de la necesidad humana, que permite al hombre irse haciendo de su propia existencia: "From being subject to nature's, and in this case the gods' will, human now become the lawgiver of nature" (JøIle, 2004, p. 401). Tal y como sucede en Esquilo, pero tratado por Goethe con mayor dramatismo, Zeus se encuentra "envidiando» la vida humana, la choza, el fuego (Und meine Herd, Um dessen Glut Du mich beneidest) y, además, está hambriento, doblemente necesitado, en su caso, de oraciones y sacrificios:

$$
\begin{gathered}
\text { "Ihr nähret kümmerlich } \\
\text { Von Opfersteuern } \\
\text { Und Gebestschauch } \\
\text { Eure Majestät } \\
\text { Und Darbtet, wären } \\
\text { Nicht Kinder und Bettler } \\
\text { Hoffnungsvolle Toren"17. }
\end{gathered}
$$

El "ardor» que Zeus envidia es algo más que carbones ardiendo y más que la saciedad y el resguardo de la Necesidad. En el poema, Prometeo establece su 'Heiling glüehend Herz' (santo corazón ardiente) como el centro de su existencia, como el centro del mundo para el sí mismo. En este primer movimiento, 
la ciencia deviene en la afirmación del ser que, en el contexto de la Aufklärung ${ }^{18}$, hay que leer como realización, como "emancipación» y como símbolo del derrocamiento del tirano ${ }^{19}$.

En este enmarcado, resulta por demás significativa la relación con el poema previo Künstlers Morgenlied, en donde el hablante localiza hier in meinem Herzen [...] das Allerheiligste (11.3-4), esto es, el "Glut» (el calor) que en el Prometheus representa el centro de la propia existencia. Asimismo, la autosuficiencia del corazón humano es un elemento determinante en el pasaje de Iphigenie auf Tauris, escrita sólo unos años después del Prometheus. Sin embargo, mientras que para Ifigenia el corazón resulta un mediador frente a los dioses para conocer su voluntad, en Prometeo el corazón es el punto de partida para la autonomía, y es en este sentido que bien vale subrayar la oposición entre la individualidad, por una parte, y la sociedad y Dios, por otra, que aparece como motivo principal en la poesía del joven Goethe (Ehrlich, 1944, p. 792). Con todo, aún queda por saber qué consecuencias tiene esta "victoria» y, más aún, queda por saber qué clase de imperio y que clase de dioses caen, simbólicamente, en el Prometheus.

\section{Desilusión y autosuficiencia, autosuficiencia y desi-} lusión

Llegados a este punto, no hay que olvidar que la «autoposesión» que experimenta Prometeo y el derrocamiento del monarca divino, son productos de una intensa lucha. El conocimiento no aparece «de pronto", no llega de la nada. El conocimiento, desde Esquilo, y aún antes, desde Hesíodo y Platón, se arrebata. Es producto de un acto de violencia y fruto, por tanto, de la profunda experiencia de la precariedad del hombre. Así, la posibilidad de alcanzar por vía del conocimiento un cierto grado de autosuficiencia, tiene una relación directa con el papel fundamental que juega en Goethe la confrontación con la soledad y con la necesidad humanas.

Puede decirse, a propósito de los vínculos del Sturm und Drang y la llustración, que Goethe, al igual que Hume, subraya el papel de los sentimientos, pero mientras que para Hume, es a través de los sentimientos que se llega al autor de la naturaleza, en Goethe se llega a tal encuentro por vía de la más radical de las desilusiones, no tanto porque no haya un autor, sino por que él parece demasiado ajeno frente a la precariedad del hombre. Vemos así, que en la quinta sección del poema se hace alusión a la titanomakhía, en donde Prometeo tomó partido por Zeus, y es entonces cuando Prometeo (¿Goethe?) habla del abandono que experimentó:

\section{Kehrt ich mein verirrtes Auge}

Zur Sonne, als wenn drüber wär

\section{Ein Ohr, zu hören meine Klage,}

Ein Herz wie meins,

Sich des Bedrängten zu erbarmen. ${ }^{20}$

El conocimiento (entendido en última instancia como conocimiento de sí, como "autoposesión») arranca, para el Prometeo goetheano, no sólo de observar la necesidad del hombre, sino de una experiencia personal de desamparo. Prometeo recuerda su infancia, las confusiones, las dudas, las angustias. Y es en medio de esta lucha solitaria que el titán irá, ambiguamente, "ganando» terreno.

Décadas después, en Dichtung und Warheit, Goethe seguirá hablando de la soledad creativa que tanto le acerca a Prometeo. Reconoce sus obras como «niños de la soledad», pues para darlos a luz ha tenido que evadir y rechazar la ayuda del hombre y cortar, como Prometeo, la relación con los dioses ${ }^{21}$, y se respira en este sentido de autoposesión, de apartamiento, en el Goethe ya viejo y reflexivo, la misma paradoja que ya está presente en el Prometheus. Se parte de la soledad para acceder a la ciencia y a la ciencia de sí, pero se vuelve a aquella soledad, en tanto se ha creado un vacío, una ausencia, un apartamiento de los dioses y de la comunidad humana.

Paradójicamente, Epimeteo, (Epi-metheus, el que ve para atrás), en el drama inconcluso de Goethe, advierte a Prometeo de su futuro sufrimiento. Es una advertencia de poco alcance, pues Prometeo (Prometheus, el que ve para adelante), reconoce y acepta de antemano el sufrimiento que él también prevé. El desafío frente a los dioses y la creación o «formación» de los humanos son dos aspectos de una misma realidad, ambos llevan al aislamiento. Prometeo se aleja de los dioses y, al mismo tiempo, está lejos de sus criaturas por su condición de Mittelfigur, después de todo, él no es ni divino ni humano. En este contexto, resulta válido decir que al lado del Prometheus, con el Cesar, el Mahoma y el Faustus, (todos ellos compartiendo el aislamiento y un final trágico), Goethe no sólo formula el problema del genio creador, sino la situación del hombre (Bergstrasser, 1949, p. 177)22.

Aunque el Prometeo de Goethe no es explícitamente castigado, sea por su gran amor a los humanos, al modo de Esquilo, o por robar el fuego, al modo de Hesíodo, constantemente hace alusión a su pesar y sufrimiento. De hecho, no sabemos si el Prometeo de Goethe está libre o encadenado ${ }^{23}$, pero lo que parece evidente es que Prometeo internaliza el castigo de la roca del Cáucaso y padece un sufrimiento más emocional que físico, en donde va de por medio «el regreso a la tierra» del que habla Michaelis:

"In the experience of disappointment we are delivered into a universe that is approximate to the universe of the Greek tragedies, in which the he- 
roic striving to overcome all mortal limits finds its downfall in the very disorderly and unpredictable course that it sets in motion. Our disappointment is the secular equivalent to the Nemesis of the gods in which Prometheus, the hero of the modern world, is brought down to earth" (Michaelis, 1999, p. 540).

\section{LO «DEMÓNICO»}

De lo anterior se sigue que el conocimiento de sí y el conocimiento en general (la ciencia y la técnica), reúnen al hombre consigo mismo y le independizan de los dioses, haciéndole, hasta cierto punto, inmune a la necesidad. Sin embargo, tal independencia, que por sí misma es signo de libertad, lleva consigo el apéndice del aislamiento que, en términos más amplios, implica también un modo de angustia o sufrimiento, lo que torna ambiguo el conocimiento y la libertad que conlleva. Se trata de las «letras pequeñas» del contrato que, más adelante, el Fausto de Goethe también obviará y que anuncian el cumplimiento de un plazo inexorable.

En el Prometheus, Goethe ya sostiene una importante tensión y ambigüedad en torno a la definición de "lo demónico», que estará presente en toda su obra. De acuerdo a Brown, Goethe no concibe un mundo dividido de manera maniquea entre lo bueno y lo malo, ni un mundo agustiniano marcado por obras de bondad, sino un mundo en donde se manifiestan los esfuerzos del hombre por establecer un orden moral (moralische Weltordung), pero que es atravesado (durchkreutz) por fuerzas incontrolables que, por sí mismas, no son buenas ni malas ${ }^{24}$, y que en el plano social quedan asociadas a los eventos revolucionarios.

Desde su juventud Goethe concibe la naturaleza como una simultánea y paradójica unidad-y-diversidad, un cósmico Wechseldauer, de un continuo cambio. Materia y espíritu, espíritu y materia, cada uno prerrequisito para la presencia del otro:

"It was a benevolent malevolence, a foolishness of infinite wisdom, a harmony of dissonances, an elaborate simplicity, a limitless play of limitations, and a tireless quest for repose. Nature was 'Polarität und Steigerung'"' (Warde, 1975, p. 176).

Este tipo de relación, que Goethe descubre en la naturaleza, está finalmente relacionada con su visión científica de la naturaleza que termina siendo, necesariamente, tan paradójica como su objeto de estudio, pues al final, en la observación se difumina la diferencia entre el sujeto y el objeto. En medio de esta paradoja, sin embargo, Goethe arriba a un nuevo tipo de conocimiento:

"To know nature was to know man and the requirements impinging upon his existence [...] The task of science was to enhance man's intuitive awareness of his bond with nature and, like all education, to illuminate the 'Bedingungen ..., unter denen man in der Welt überhaupt, sodann aber in besonderen Kreisen existieren kann'" (Warde, 1975, p. 177) ${ }^{25}$

Frente a esta condición «circular» que Goethe descubre entre la naturaleza y el ser humano, el conocimiento llama a una cooperación consciente con la «Voluntad» manifiesta en la Naturaleza. De por medio está la actualización del problema de la libertad y sus límites, que en su momento C. G. Jung verá más claramente definido en el Faustus (Bishop, 2008a, p. 62). Cada uno ha de cargar con este dilema, como se carga con la antorcha del conocimiento, encontrándose el punto nodal en un tipo particular de rendición frente a los límites que la Naturaleza impone al ser: "Yet for Jung, as for those 18th-century classical thinkers on whom he drew, this totality, this fulfillment, can only be found -paradoxically- in an acceptance of the limitations of the self" (Bishop, 2008b, p. 29) ${ }^{26}$.

En Goethe, el conocimiento llama a esa paradójica «acción-sumisa» que ya está presente en el Prometheus y que también se dejará escuchar en Dichtung und Warheit, así como en su Naturphilosopie y su $\mathrm{Na}$ turtheologie. Como Korff lo señala, la libertad significa para Goethe algo más que la libertad humana en función de la razón, es ante todo, una «necesidad divina» que se origina en la profundidad, más allá de la razón, y que trabaja entre nosotros (Bergstrasser, 1949, p. 187, nota 121).

En el arribo a esta toma de consciencia podemos ver que Goethe, en definitiva, no dejó de ser un hombre religioso y que su rebelión frente a los dioses fue, en realidad, una rebelión frente a una tradición religiosa, frente al modo predominante en el mundo cristiano de entender lo Trascendente. De ahí que la temprana recepción del poema tenga que ver con la llamada Spinoza-Streit, que envolvió a Mendelsohn, Lessing y Jacobi y que traería como consecuencia un atheistisches Skandalon, y teniendo esto en mente, podemos finalmente ver los alcances de la última sección del poema, que nos sitúa en el momento en que Prometeo pregunta:

\section{"Hat nicht mich zum Manne geschmiedet \\ Die allmächtige Zeit \\ Und das ewige Schiksal, Meine Herrn und deine? ${ }^{27 "}$}

El poema revela aquí su cercanía a Spinoza y, por tanto, a un concepto de Dios en el que se rechaza cualquier tipo de antropomorfismo para entenderlo, $y$ en donde Goethe parece querer revelar al ens $a b$ solute infinitum ${ }^{28}$. El conocimiento y la libertad se circunscriben a una paradójica relación con el Tiempo y el Destino, en donde el Tiempo hace a Prometeo, pero 
en función de lo que Prometeo es desde sí mismo, desde el plan o diseño tejido por el ewige Schicksal. Condición a la que también están sujetos los dioses de la tradición ${ }^{29}$.

La lectura que Lessing y Goethe hicieron de la obra de Spinoza, ciertamente pudo dar por resultado una interpretación no del todo correcta, pues la discusión de si Spinoza era realmente panteísta se mantiene vigente (Deschepper, 1992, pp. 151 y ss.), pero lo que en cualquier caso resulta evidente, es que en el centro del Prometheus se reconoce una condición que está más allá de los dioses, o sobre ellos. Condición que articula el ser y el "devenir» del hombre y le sitúa en una relación única frente a la Naturaleza. Ambigüedad o coincidentia oppositorum que se hará patente en el comentario de Goethe al Système de la nature ou des lois du monde physique \& du monde moral (1770) de Holbach, en donde, además de fijar la postura de los Naturphilosophen, habla de ese "algo" que ve en la Naturaleza "nuestro ídolo», que "...aparecía como perfecto libre arbitrio y, de nuevo, algo que trataba de contrarrestar esta libertad" (Mason, 2001, pp. 113-114).

El conocer y la verdad tienen importancia sólo cuando implican la unión de espíritu y naturaleza («Dios» y el mundo). Y existen, de acuerdo a Schiller, personalidades en la obra de Goethe que ejemplifican tal reconciliación: "It was in this sense that Schiller understood the figure of Natalie in Whilhelm Meister as holy and human at the same time" (Bergstrasser, 1992, p. 193).

En esta condición, el ser humano alcanza un tipo de reconciliación o síntesis entre el ser espiritual y la Naturaleza que representa el ideal rosacruz del que Goethe participa (Bergstrasser, 1992, p. 195), y la labor "prometeico-educativa», en este paradójico modo de conocer-ser y conocer al Otro, comprometería a Goethe en una tarea que tendría por cometido la combinación del arte con la ciencia (Warde, 1975, p. 177). Si bien en esto cabe subrayar que, a diferencia de Schiller, Goethe no percibe una dicotomía entre la realidad y el ideal natural. La inconformidad del hombre es reflejo de la propia inquietud de la Naturaleza: "Man was restless because nature was restless..." (Warde, 1975, p. 180), por lo que Warde agrega que en lugar de la heroica conquista de la voluntad, Goethe apunta a una clase especial de rendición que le acerca más a Hölderlin, pues se mantendrá en la línea de señalar que la reconciliación entre la razón y la historia (el ser y el quehacer del hombre) será siempre parcial.

\section{CONCLUSIONES}

Se puede afirmar que el Prometheus es un símbolo de la rebelión ilustrada, que desde la consolidación del ser individual se enfrenta a la tiranía de las circunstancias bajo una intención: establecer un orden, un orden nuevo, "humano». Se puede afirmar también, que en esta obra lo que Zeus envidia, por encima de la liberación (relativa) del hombre frente al imperio de la Necesidad, es el centro desde el cual Prometeo actúa, su 'heiling glüehend Herz'.

Queda por responder, sin embargo, o al menos tratar de especificar más claramente, cuáles son los yugos que Prometeo «realmente» quebranta o, en otras palabras, qué yugos el hombre, de acuerdo a lo que anuncia el Prometheus, puede "realmente» quebrantar y, cuales no. En el trance de hacerse a sí mismo, Prometeo parece liberarse y liberar al hombre del azote de la Necesidad y de la enfermedad, al tiempo que el corazón le guía para verse librado de la muerte en la lucha contra las fuerzas adversas (representadas, en el caso de Prometeo, por los titanes) ¿pero hasta qué punto o en qué sentido todo esto se logra «realmente»?

Lo que parece quedar claro es que el «nuevo» orden, el orden humano, no es definitivo, ni representa, por decirlo de algún modo, el encuentro último con el bienestar y la salud. Se parte de la soledad para acceder a la ciencia y a la ciencia de sí, pero como hemos visto, la primera consecuencia de esto es una abertura, el distanciamiento, la creación de un vacío. El apartamiento de la tradición, del dogma y de los dioses, crea lo que Max Weber Ilama, la desilusión frente al desarrollo de la modernidad (Gerth y Wright, 1946, p. 50). El Prometheus, por tanto, representa también la desilusión del ser ilustrado, del ser que pretende liberarse por vía de la chispa racional (del saber científico y tecnológico) del imperio de la necesidad, de las tiránicas circunstancias sociales y de los antiguos dioses, pero que al final, sólo se encuentra, desde un nuevo plano, con fuerzas que le atraviesan y le revelan su condición ambigua. Hoy bien sabemos que el dominio sobre la naturaleza, el avance científico y tecnológico e, incluso, el avance filosófico, teológico y metafísico, o en suma, el saber intelectual y práctico del homo faber, no se conforman como un "avance» hacia un lugar de permanente bienestar y descanso. De entrada, porque el conocimiento y el dominio, la acción del hombre en la naturaleza, llevan el signo de la depredación, el signo que ya muestra el robo de la «flor de Vulcano", lo cual demanda algún tipo de retribución.

Frente al tirano y la pequeñez de la concepción antropomórfica (tradicional) de los dioses, frente ellos, Goethe y Prometeo se rebelan y se burlan. Pero no en menor grado se pone de manifiesto que desde el "nuevo tiempo" y desde la "nueva ciencia», la que se burla es la Naturaleza. Se burla del continuo intento por imponerle un orden, del intento por reducirla y domeñarla mediante el entendimiento. Y es partir de esta confrontación, que el Prometheus nos arroja hacia un Früzeit, que contrasta con el Neue Zeit. Es un retorno al tiempo que antecede a Zeus, desde el que 
surge otro intento, el de la reconciliación con los antiguos dioses: Prometeo reconciliándose con Cronos, Prometeo el melancólico saturniano ${ }^{30}$, es Goethe en el asombro de la Naturaleza.

Un retrato de la condición circular del hombre está en el Prometheus. Recorrido iniciático que muestra cómo el titán se afirma y se hace a sí mismo, pero sólo para volver al punto de partida. ¿Puede Prometeo y el hombre prometeico hacer otra cosa? ¿Pueden ambos librarse de las vanas esperanzas o dejar de pretender situarse en el lugar de los dioses, ya sea para intentar superarlos o para intentar "entenderlos»? El camino de vuelta revela la fuerza incontenible y el ansia del hombre por traspasar los límites, manifestación, al fin, de su propio Sino, que hay que distinguir, por cierto, de ese otro sino circunstancial que el hombre sí puede (y debe) romper. Pareciera que el hombre esta "hecho» y destinado, que la forma humana corresponde a su tendencia a traspasar y salir.

Cierto, y ya se ha dicho, el día siguiente a la transgresión hay nuevos muros, pero con la paradoja del retorno a Cronos, Goethe parece querer comunicar un nuevo tipo de conocimiento o un nuevo tipo de libertad. Después de todo, no hay forma de volver exactamente al mismo punto. Prometeo vuelve, pero se ha hecho a sí mismo (consciente), de modo que el retorno a Cronos implica, como señalaba Korff, más que la libertad humana en función de la razón, el discernimiento de una necesidad que se origina más allá de la razón, que trabaja entre nosotros y que atañe al fin del Naturaleza (Bergstrasser, 1949, p. 187, nota 121) y frente a este Fin, Goethe y Prometeo parecen capitular en sus esfuerzos.

Vale aquí, sin embargo, la pregunta: ¿Pero no será este un nuevo modo de querer controlar, de querer trascender limites, de querer entender y domeñar, ahora mediante la búsqueda de un acuerdo, mediante la «coacción» del rendimiento y la sumisión voluntarios?

Hay que aclarar, entonces, que cuando Goethe habla de obedecer a la Naturaleza, al parecer hay que ver en ello una demanda paradójica que a momentos se torna irónica, porque no hay forma de obedecer, en tanto no hay forma de predecir. El orden que el hombre trata de construir y el orden que el hombre trata de discernir en la Naturaleza, se verá siempre atravesado por las mismas fuerzas que se burlan de él. Es este "entender», entender que no hay modo de entender, lo que, finalmente, parece no sólo revelar la condición de la Naturaleza, sino completar la visión del hombre, y es la consciencia de su propia disonancia lo que le acerca a ella ${ }^{31}$, a la Naturaleza. De ahí que Goethe asemeje el ímpetu humano y los eventos revolucionarios con las tempestades y los terremotos, pues la inconformidad del hombre es reflejo de la propia inquietud de la Naturaleza. ¿Entonces es esto un llamado al irracionalismo, un llamado a deponer todo intento de orden y una renuncia al "movimiento» y la afectación frente al otro? Pues después de todo, ¿para qué o cómo actuar?

La respuesta del Prometheus es tajante: NO. El hombre puede y debe enfrentar la tiranía (ideológica, social, religiosa) y siempre, lo reconozca o no, se sentirá movido frente al otro, aunque le aten, incluso, como a Prometeo. Y el que «no todos los frutos maduren», no lleva al hombre a dejar de actuar. De hecho, aunque no todos los sueños maduren (y podríamos agregar, «irónicamente», aunque no todos los hombres maduren), parece que la condición del ser humano es actuar siempre, movido por la (¿vana?) esperanza, en donde, desde luego, se torna también irónico dudar si la esperanza es vana ${ }^{32}$. Este es su SINO, lo que, sin embargo, no implica asumir un fatalismo, más reconocerse inmerso en una condición que en el Faustus se rebelará como «divina» o «demónica» (Warde, 1975, p. 182).

Es la contradicción, la ambigüedad y la ironía lo que hacen del ser humano más que una máquina «medible», "comprensible», "calculable» y "predecible», y son tales condiciones las que revelan su vínculo con la Naturaleza viva, y que permiten situar al Prometheus muy lejos del triunfalismo ilustrado o moderno. El saber tiene para Goethe, el mismo sabor de la ironía que mueve al hombre y a la Naturaleza, y entonces, claro, no hay para qué asustarse, no hay para qué asustarse de uno mismo, como diría Nietzsche en el Viajero y su sombra ${ }^{33}$.

Habrá que aclarar, con todo, que la nota distintiva de Prometeo es la «afectación» frente al otro. Nueva paradoja: el límite es el otro y el otro es el límite que se quiere traspasar (¿ ¿egoístamente?). Prometeo no es sólo la individualidad incontenible, sino el ser inconteniblemente atravesado por el pathos. Lo que distingue, en este sentido, al Prometheus goetheano de las obras características del Sturm und Drang es, precisamente, la acción reflexiva frente al otro. Prometeo no sólo es la representación de la individualidad autoafirmativa, sino la reafirmación del ser por el otro, por la philía. En función del hombre, al cual ama, es que Prometeo busca establecer un «nuevo» orden, orden que se verá siempre atravesado, que será siempre parcial, pero que da sentido, que va marcando una diferencia entre la choza humana y el reino celestial del monarca. Es el intento por ser y estar con el otro, y la fascinación frente a él, lo que en última instancia marcan el signo del robo y de la lucha. Se trata del intento de trasgresión marcado por la Filantropía ${ }^{34}$.

No queda sino decir que, en este caso, también se topará Prometeo, y con él, el ser humano, con los límites de su soledad, con los límites de su individualidad, con la paradoja de reafirmarse a sí mismo para ser, y de intentar, al mismo tiempo, ser con el otro (¿quién 
se impone a quién?). Contradicción que arroja a Prometeo al plano liminal de la Mittelfigur. Más de nuevo aquí, el intento de Prometeo y del hombre, será incesante, y será quizá la propia imposibilidad de traspasar la individualidad, lo que les arroje con más fuerza y lo que, en último término, construya y mantenga el ficticio puente del vínculo humano, o el holograma en sí, de la humanidad, de lo que es ser humano. Puente irreal, tan irónico como intangible, fruto de una rela-

\section{NOTAS}

1 El Sturm und Drang será el intento por trascender el sobresentimentalismo y la caracterización "objetiva» que tendía a predominar en el teatro y que era clara muestra de la expansión del racionalismo a los terrenos del arte. Los representantes del Sturm und Drang se arrojarán hacia un intento por llegar a la expresión de la problemática humana con sus extremos emocionales y, más aún, con la impureza inherente de las motivaciones personales. El término apareció por primera vez en la obra Sturm und Drang de Friedrich Maximilian Klinger (1776), originalmente intitulada Wirrwar, y Johann Georg Hamann ha sido considerado el ideólogo del movimiento. Herder y Goethe fueron, por su parte, de entre sus representantes más destacados.

2 "Ist's weise, daß man dich verdamme, Gebenedeite Gottesflamme, Allfreie Denk- und Druckerei?" (p. 63).

3 De aquí, entonces, que una de las preguntas que tenga que responderse aquí es, ¿̇hasta qué punto puede situarse a Prometeo, realmente, como figura del Sturm und Drang o en que sentido puede serlo? Esto se tratará en las conclusiones.

4 Esta ambigüedad es la que también parece estar presente en la actitud paradójica del Prometheus goethiano que clama, "Ich bin kein Gott", pero que al mismo tiempo asume la prerrogativa divina de "crear» o "formar» (como un second maker) a los seres humanos.

5 En el curso de la Revolución científica, las ideas de la recuperación de los efectos adversos del «pecado original» fueron reforzadas por un conjunto de ideas heredadas de la teología antigua, en particular, del Hermetismo. "Los escritos neoplatónicos más mágicos y el Corpus Hermeticum actualizado por los neoplatónicos florentinos, contenían más que una velada expectativa de que los iniciados en el hermetismo podrían ascender al nivel de la iluminación mística, con una variedad de beneficios que incluían la posibilidad de ser transformado en un poderoso Magi [...]. Como han apuntado Pagel, Rossi, Walker y Yates, las aspiraciones de la ciencia experimental estaban íntimamente entrelazadas con la suerte del Magus renacentista" (Webster, 1988, pp. 91-92).

6 A propósito hay que notar que desde una temprana edad Goethe manifestó un fuerte interés por la alquimia (cf. Friedenthal, 1963, p. 67) y por la masonería, como se verá a continuación. Ambos, la alquimia y la masonería se caracterizan por el resguardo de símbolos y significados vinculados al Hermetismo y a la figura del mago (cf. Magee, 2001, pp. 53-54), y ambos viven, hacia finales del siglo XVIII y principios del XIX, un importante apogeo en el contexto germano (Gray, 1952, p. 15). ción transgresiva, en tanto rompe, o intenta romper, los propios límites frente al otro y los límites del otro. Y es por tanto, esa sed, esa confirmación del Sino y de la vana esperanza, los que, paradójicamente, construyen y dan sentido a lo que no es, o a lo que no era. No hay olvidar, a propósito, que Prometeo no es creador ex nihilio, sino figura del segundo creador, figura del artífice y del artificio.

7 El primer documento que se tiene escrito por Goethe es su solicitud de admisión a una Logia y a lo largo de su vida, Goethe sería un militante activo de la masonería (cf. Friedenthal, 1963, pp. 31 y ss.).

8 El poema Prometheus sería escrito por Goethe entre 1772 y 1774 , siendo publicado por primera vez en 1789. En este trabajo se utilizará como principal referencia el poema en su idioma original, así como la traducción al inglés hecha por Michael Hamburger en Middleton (1994), y la traducción al español hecha por José Luis Reina, en Goethe (1999).

9 Hederich encaminó sus esfuerzos al mejoramiento de la enseñanza, a la divulgación de la ciencia y a las ciencias que hoy llamamos "subsidiarias» (escribió varias «introducciones» a las ciencias y textos sobre genealogía, heráldica y cronología, entre otros), así como a la elaboración de diccionarios y léxicos de griego y latín. La obra de Hederich, y en especial, su Lexicon Mythologicum (1724) fue el punto de referencia fundamental para los artistas y poetas del Romanticismo germano, como fue el caso de Goethe, Schiller y Heinrich von Kleist. En el tratamiento dado a Prometeo: "Hederich (p. 2092) describes an ancient intaglio where Prometheus is seen sitting moulding his humans, with a butterfly, symbolizing the human soul, hovering over him. In the first act of the drama, Prometheus is merely fashioning inanimate statues, to which Minerva gives life. In the poem, which stresses Prometheus's singlehanded achievements, he seems both to mould his humans and to breathe life into them, not unlike the myth of Pygmalion, with which Goethe's accounts of Prometheus show some significant similarities" (Jølle, 2004, p. 400).

10 Actualmente existe duda en cuanto a la autoría de esta obra tradicionalmente atribuida a Esquilo (West, 1990).

11 En la obra de Hesiodo, la Teogonía parece enfatizar el fracaso de Prometeo («el de torva astucia») para engañar a Zeus («el prudente» o "providente»), y en Los trabajos y los días, el acento recae en las consecuencias que tiene, para Prometeo y para los humanos, el conflicto con Zeus.

12 Platón, por su parte, presenta a Prometeo ofreciendo la sabiduría técnica a los hombres, simbolizada por el robo del fuego, mientras Zeus, es retratado como un Dios benevolente, justo y preocupado por el bien de los hombres, ofrece las cualidades que permiten la vida en común (aidos y dike). En este último caso se trata, por tanto, de la puesta en escena de acciones complementarias entre Prometeo y Zeus que favorecen el establecimiento del orden humano.

13 "y como un jovenzuelo que cardos decapita ejercítate en robles y altas montañas" (En la traducción al español se utilizará la realizada por José Luis Reina, en Goethe (1999). 
14 "Tienes que dejarme mi tierra sin embargo y mi choza que tu no has hecho y mi hogar cuyo fuego me envidias".

15 Intención que parece ser de origen neoplatónico y que proviene de Proclo (más que de Plotino), quien creía que el Uno debe emanar para llegar a completarse. La elaboración de esta idea, en la creencia de que Dios viene a ser auto-consciente, libre y completo a través de la cognición humana, fue central para el hermetismo y se encuentra presente Hegel (Magee, 2001, pp. 21 y ss.).

16 En este sentido, Garcia Bacca agrega que en el mundo trágico de los griegos circulaba la sentencia: "La Suerte (Azar) es el tirano de todos los dioses».

17 "Aliméntase parcamente de ofrendas y aliento de oraciones vuestra majestad y vivirías en la miseria si no fueran niños y mendigos locos llenos de esperanza".

18 La Aufklärung sería la versión germana de la llustración, en donde la fuerza de la razón se mezcla con el misticismo, la religión, el esoterismo, la filosofía metafísica, el vitalismo y la sensibilidad artística. Es difícil saber hasta qué punto la Aufklärung correspondería, más bien, a un Renacimiento que llega con retraso al suelo germano. Es probable que el inicio de la Aufklärung comience en el Palatinado de Heidelberg, a inicios del siglo XVII (cf. Yates, 1982, p. 285)

19 "The socio-economic aspect is [...] emphasized by the neologism 'Opfersteuern' (1. 16), which conflates devotion with revenue, and the almost feudal reference to the 'Majestat' (1. 17) of the gods" (Jølle, 2004, p. 402).

20 “... dirigía mi ojo extraviado al sol, como si allí hubiera un oído para oír mi queja, un corazón como el mío que de mi apuro se compadeciera".

21 "My works that had met with so much approval were children of solitude and after my relation to the world had broadened, there was no lack of inventive power and enthusiasm, but the execution faltered, for I had no real style either in prose or in verse, and in each new pice of work, according to the nature of the subject, I had to grope forward and make new experiments. Since in this I had to reject, to exclude the help of men, I cut myself off, like Prometheus, from the gods as well..." (Kerényi, 1997, p. 15).

22 En este sentido conviene señalar, además, la posibilidad de que la segunda parte del Fausto, en donde el protagonista adquiere caracteres prometeicos, haya sido inspirado por Napoleón, en tanto éste representa al europeo prototípico de la época, un ser humano que ejecuta en el campo de la política lo que Fausto explora en el campo del conocimiento y la experiencia (Lutzeler, 2000, p. 104)

23 Recordemos que Goethe también trató de escribir un Die Befreiung des Prometheus, de lo que cabría suponer que en el Prometheus el titán está encadenado.

24 Como ejemplo, Brown toma el caso del terremoto de Lisboa que desató, en su momento, toda una serie de cuestionamientos acerca de la providencia de Dios. Si bien Goethe era un niño cuando éste tuvo lugar, al parecer marcó de manera importante su concepción de Dios (1992, pp. 476-477).
25 Warde toma la cita de Goethe de la revisión que el poeta hace a la obra Gabriele de Johanna Schopenhauer, en Gedenk-ausgabe der Werke (1923), editada por Ernst Beutler.

26 Jung sostuvo que la tarea de la psicología es lograr la coordinación o síntesis de los opuestos, lo que implica la completa obediencia a las leyes fundamentales de la naturaleza humana, pues sólo entonces podrá descubrirse la "vía intermedia» que conduce al óptimo vital: “... there can positively be no higher moral principle than harmony with natural laws that guide the libido in the direction of life's optimum [...] The optimum can be reached only throug obedience to the tidal laws of the libido..." (Bishop, 1999, p. 2). Si bien hay que notar que a diferencia de Goethe, para quien la Naturaleza aún mantiene un vínculo con lo Trascendente, en Jung la tendencia es hacia la psicologización de ambos.

27 "¿No me ha forjado hombre el poderoso tiempo y el eterno destino, mis señores y los tuyos?"

28 "Per Deum intelligo ens absolute infinitum hoc est substantiam constantem infinitis attributis quorum unumquodque æternam et infinitam essentiam exprimit" (Spinoza, 1677, versión electrónica).

29 Es en este contexto que hay que entender porqué Lessing, en torno a la discusión que él y Jacobi sostienen alrededor del Prometheus goetheano, llega a asegurar que los «conceptos ortodoxos» sobre Dios ya no eran para él, declarándose partidario de Spinoza (Colomer, 2001, pp. 21-22).

30 Una de las características del hermetismo es la reivindicación de Saturno (el Tiempo), como representación del carácter melancólico del genio. El saber se encuentra cubierto de un manto de ambigüedad y se distingue del saber triunfante de la llustración (Yates, 1982, pp. 90 y ss.).

31 "Man was restless because nature was restless..." (Warde, 1975, p. 180).

32 Conviene recordar aquí que el acicate para el conocimiento, o para la potencialidad del conocimiento parece ser, precisamente, la esperanza o, más propiamente, las «vanas esperanzas». El hombre no puede dejar de esperar, no puede dejar de actuar, y esta es, quizá, su desgracia y su virtud (Garcia Bacca, 2001, p. 30).

33 “...las locuras del hombre constituyen parte de la fatalidad, lo mismo que sus actos de gran sabiduría; ese miedo a la creencia en la fatalidad es también fatalidad. Tú mismo, pobre ser temeroso, eres la invencible Moira que reina por encima de todos los dioses; para todo lo que está por venir tú eres la bendición o la maldición, y, en todo caso, la traba que sujeta al hombre, incluso al más fuerte; en ti, todo el porvenir humano está determinado de antemano; de nada vale que te asustes a ti mismo." (Nietzsche, 1999, p. 181).

34 "Mientras que la gloria de Zeus reside en haber conquistado el poder supremo, la gloria de Prometeo está en ese amor suyo a los humanos que le ha llevado a ofrecerles el fuego, la esperanza y las técnicas. Philantropía (palabra que aparece por primera vez en griego en esta tragedia) y philotechnía (vocablo documentado, más tarde, en Platón), son los motivos del Titán. Su excesivo amor a los hombres le atrajo la enemistad de los dioses. Pero era digna la apuesta" (Garcia Gual, 1995, p. 147). 


\section{BIBLIOGRAFÍA}

Bergstrasser, Arnold (1949), "Goethe's View of Christ", Modern Philology, 46 (3), pp. 172-202, p. 177, p. 187, p. 193-195.

Bishop, Paul (1999), "Introduction". En Bishop, Paul (ed.), Jung in Context. A Reader, Londres, Routledge, pp. 1-23, p. 2.

Bishop, Paul (2008a), "Jung's early reception of Goethe and Faust, 1880-1916". En: Bishop, Paul, (ed.), Analytical Psychology and German Classical Aesthetics. Goethe, Schiller, and Jung. Vol. 1, East Sussex, Routledge, pp. 42-80, p. 62.

Bishop, Paul (2008b), "Thinker: Carl Jung”, New Humanist, 123 (1) enero/febrero, p. 29.

Brown, Robert H. (1992), “The 'Demonic' Earthquake: Goethe's Myth of the Lisbon Earthquake and Fear of Modern Change", German Studies Review, 15 (3), pp. 475-491, pp. 476-477, p. 483, p. 387.

Bürger, Gottfried A. (1835). Sämmtliche Werke, Gotinga, Dietrich, p. 63.

Colomer, Eusebi (2001), El pensamiento alemán de Kant a Heidegger. II, España, Herder, pp. 21-22.

Deschepper, Jean-Pierre (1992), “El Spinozismo”. En: Yvon Belaval (dir.), Racionalismo, Empirismo, Ilustración, Madrid, Siglo XXI de España Editores, S.A, pp. 130-157, pp. 151 y ss.

Durand, Gilbert (1993), De la mitocrítica al mitoanálisis. Figuras míticas y aspectos de la obra, Barcelona, Anthropos, p. 33

Ehrlich, Godfried (1944), "Goethe, Freiheit und Sturm-und-Drang", Pmla, 59 (3), pp. $792-812$, p. 792

Friedenthal, Richard (1963), Goethe: his Life and Times, Londres, Weidenfeld \& Nicolson, pp. 31 y ss.

García Bacca, Juan David (2001), Sobre filantropía. Tres ejercicios literario-filosóficos, Barcelona, Anthropos, pp. 28-29, p. 30, p. 46.

Garcia Gual, Carlos (1995), Prometeo, mito y tragedia, Madrid, Hiperión, p. 147, pp. 191-192.

Gerth, Hans H., y Wright Mills, Charles (1946), From Max Weber: Essays in Sociology, Nueva York, Oxford University Press, p. 50.

Goethe, Johann W. (1999), "Prometeo". En: Goethe, Johann, W, (ed.), La vida es buena (cien poemas), Madrid, Visor, pp. 25-27.

Gómez de la Serna, Ramón (1996), Obras completas I. Barcelona, Galaxia Gutenberg-Círculo de Lectores, 101.

Gray, Ronald D. (1952), Goethe The Alchemist. A Study of Alchemical Symbolism In Goethe's Literary And Scientific Works, Londres, Cambridge University Press, p. 15.

Hanratty, Gerald (1986), "Hegel and the Gnostic Tradition: II", Philosophical Studies, 31 (87), pp. 301-325, p. 308
Iølle, Jonas (2004), "Prince poli \& savant: Goehte's Prometheus and the Enlightenment", The Modern Language Review, 99 (2), pp. $394-415$, p. 395 , pp. $398-399$, p. 400 , p. 401 , p. 402

Kerényi, Carl (1997), Prometheus. Archetypal Image of Human Existence, Nueva Jersey, Princeton University Press, p. 15.

Koselleck, Reinhart (1985), "Neuzeit': Remarks on the Semantics of the Modem Concept of Movement". En: Koselleck, Reinhart, Futures Past: on the Semantics of Historical Time (pp. 238-258), Cambridge, The MIT Press, pp. 238-258, pp. 238-239.

Leidner, Alan C. (1989), "A Titan in Extenuating Circumstances: Sturm und Drang and the Kraftmensch", Pmla, 104 (2), pp. 178189.

Lutzeler, Paul Michel, (2000), "Goethe and Europe", South Atlantic Review, 65 (2), pp. 95-113, p. 104

Magee, Glenn Alexander (2001), Hegel and the Hermetic Tradition, Ithaca, Cornell University Press, p. 53, p. 21.

Mason, Stephen F. (2001), Historia de la ciencias. 3, Madrid, Alianza Editorial, pp. 113-114.

Michaelis, Loralea (1999), "The Wisdom of Prometheus: Kant, Marx, and Hölderlin on Politics, Disappointment, and the Limits of Modernity", Polity, 31 (4), pp. 537-559, p. 540, p. 542, pp. 550-551.

Middleton, Christopher (ed.) (1994), Goethe. The Collected Works. Selected Poems, EE. UU., Princeton University Press.

Nietzsche, Friedrich (1999), El viajero y su sombra. Segunda parte de 'Humano demasiado humano', Madrid, Edaf, p. 181.

Spinoza, Baruch (1677), "Ethica. Ordine geometrico Demonstrata et in quinque partes distincta". En: Spinoza, Baruch, Opera Posthu$m a$, [en línea], disponible en: http://www.thelatinlibrary.com/ spinoza.html, [consultado el 20/04/2011].

Warde, Anton (1975), "Goethe, Schiller, Faust, and the Ideal: The Genesis of Irony in Faust", The German Quarterly, 48 (2), pp. $175-186$, p. 176, p. 177 , p. 180 , p. 182

Webster, Charles (1988), De Paracelso a Newton: la magia en la creación de la ciencia moderna, México, Fondo de Cultura Económica, p. 77, p. 100.

West, Martin L. (1990), "The Authorship of the Prometheus Trilogy". En: Studies in Aeschyus, Sturrgart, Teubner, pp. 51-72.

Yates, Frances A. (1982), La filosofía oculta en la época isabelina, México, Fondo de Cultura Económica, p. 90 y ss, p. 285. 